\title{
Entropy-Cloud Model of Heavy Metals Pollution Assessment in Farmland Soils of Mining Areas
}

\author{
Juan Yang'*, Haorui Liu ${ }^{2}$, Xuedou Yu ${ }^{3}$, Zhixuan Lv ${ }^{3}$ Fenghua Xiao ${ }^{1}$ \\ ${ }^{1}$ School of Economics and Management, Dezhou University, Dezhou 253023, China \\ ${ }^{2}$ School of Automotive Engineering, Dezhou University, Dezhou 253023, China \\ ${ }^{3}$ Science and Technology Department, Dezhou University, Dezhou 253023, China
}

Received: 25 October 2015

Accepted: 20 February 2016

\begin{abstract}
An entropy-cloud model is proposed to deal with soil heavy metal pollution assessment based on entropy and cloud model theory. Parameters of the cloud model of each heavy metal level are calculated with the chosen indicators, and hybrid entropy weights are determined based on Shannon entropy and the analytic hierarchy process (AHP) to generate an entropy-cloud model of all indicators. Certainty degrees of each level are calculated by the entropy-cloud model, and the fuzzy entropy of certainty degrees is calculated to indicate the complexity of heavy metal pollution. Heavy metal pollution of 10 farmland soils in mining areas is assessed by the entropy-cloud model. Comparative studies with variable fuzzy sets, artificial neural network, and normal cloud model show that the entropy-cloud model is effective and intuitive, which can assess the soil heavy metal pollution from two aspects of level and complexity. Different from other methods, this model provides a new way to assess soil heavy metal pollution.
\end{abstract}

Keywords: information entropy, cloud model, soil heavy metal pollution assessment, analytic hierarchy process (AHP)

\section{Introduction}

Soil heavy metal pollution is a threat to regional soil environmetal security and ecological balance as well as physical health and continuous development of society and economy as the heavy metal transfers to crops and accumulates there during the process of a series of chemical and biological actions. It is a necessary preparation for pollution control and ecosystem restoration for mastering the actual pollution condition comprehensively for reasonable analysis and evaluating soil environment [1].

*e-mail: yangjuan@dzu.edu.cn
Heavy metals pollute the soil in mining areas through mining area construction activities such as mining, waste discharge, reclamation, and so on, which makes natural soils and reclamation soils rich in heavy metals and lowers soil quality [2]. Therefore, scientific evaluation of soil heavy metal pollution is the first step for carrying out soil environmetal risk classification and risk control zoning of heavy metals contamination in soil [3]. To guarantee pollution control, farmland security is an important way to solve the problem of soil pollution in China.

Soil heavy metal pollution evaluation is to identify the state and attribute of soil heavy metal pollution through multivariable processing with the method of qualitative and quantitative transformation. The common methods 
that have been adopted to assess soil heavy metal pollution include single factor index, Nemerow integrated index, fuzzy nearness, geo-accumulation index, potential ecological risk index, and so on [4-6]. However, some defect still exists in domestic and international evaluation that may mislead the final decision. Firstly, in common determination of evaluation strategy, the input of heavy metal is single and definite, while for the whole evaluation area, heavy metal content differs among different space. So contradicting what exists between them will lead to the fuzziness of pollution assessment.

An entropy-cloud model was proposed to deal with the soil heavy metal pollution assessment based on entropy and cloud model theory. The conversion between qualitative evaluation and quantitative parameters is realized based on the entropy-cloud model, which aims at solving fuzziness of grade belonging and randomness in expert assessment on the basis of the cloud model. At the same time, the model can reasonably deal with heavy metals in different grades so that comprehensive judgment can be made. During that process, fuzzy entropy is used as the second dimensional parameter to evaluate the assessment and reflect on the complexity of heavy metal pollution, which provides a new solution. Finally, Shannon entropy and AHP were proposed aiming at the weights of all indicators to prevent the situation of not combing objective weight with subjective weight in the assessment. Heavy metal pollution of 10 farmland soils in mining area was assessed by the entropy-cloud model. Comparative studies with the BP neural network method, variable fuzzy sets, artificial neural network, and normal cloud model show that the entropy-cloud model is effective and intuitive.

\section{Experimetal Procedures}

\section{Assessment Model}

\section{Cloud Model}

The cloud model is a conversion model with uncertainty between qualitative concept and quantitative expression first proposed by DeYi Li [7]. The normal cloud model proved to have universality, and suitability now has gradually developed to be a cognition model with perfect theory and has been used in time series prediction, spatial data mining, risk assessment, and so on [8-11].

The cloud model constructs the mapping between qualitative concept and quantitative expression through which the fuzzy and random can be reflected and combined. Let $U$ be a universe in accurate value, which corresponds to qualitative concept $A$. There exists a random value satisfying the formula of $y=U_{A}(x)$ steadily for an arbitrary element in the universe, reflecting the certainty degree of $x$ corresponding to concept $A$. The distribution of $x$ in the universe of $U$ is called cloud model or cloud for short [12]. In soil heavy metal pollution evaluation, $U$ is the limit value of pollution level for a specific metal while $A$ expresses the corresponding pollution concept, such as grade I representing non-contaminated soil. $x$ is the pollution index in single factor. Single pollution index is the ratio of the measured values of a certain heavy metal to corresponding value regulated by national quality standard [13].

Cloud model is a set of parameters $\left(E_{x}, E_{n}, H_{e}\right)$ that can express the digital characteristics of certain heavy metal pollution to show the uncertainty of heavy metal pollution.

Expectation $E_{x}$ is the most typical sample point relating to concept quantization in the soil heavy metal pollution universe.

Entropy $E_{n}$ can be measured to indicate the concept of soil heavy metal pollution that will become more macroscopic as entropy increases. Another measure of fuzzy concept is the acceptable value range in the soil heavy metal pollution universe.

Hyper entropy can be used to show the uncertainty of entropy, revealing the randomness of the representative pollution concept and the relationship between fuzziness and randomness.

Conversion between qualitative concept and quantitative expression can be realized by a cloud generator. The operating steps are as follows [14]:

1. Random number $E_{n}^{\prime}$ is achieved, taking $E_{n}$ as expectation and $H_{e}$ as standard deviation.

2. Random number $x$ is achieved, taking $E_{x}$ as expectation and absolute value of $E_{n}^{\prime}$ as standard deviation. $x$ is called cloud droplet in the soil heavy metal pollution universe.

3. $y$ is calculated in the formula of $y=e^{\left.-(x-E x)^{2} / 2(E n)^{\prime}\right)^{2}}$, which provides the certainty degree for $x$, which corresponds to soil heavy metal pollution concept $A$.

4. The first and the second steps are repeated until cloud droplet number reaches $N$.

\section{Information Entropy}

Even though a cloud model forms the main body of the assessment model, information entropy is still needed to be used to construct entropy-cloud model in considering the multi-index weights and assessment results.

Shannon took entropy to measure information, which lays a foundation of modern information theory [15]. Entropy weights are not a significance index for the practical meaning of a certain parameter, but for the comparison among all the parameters on the influence to the comprehensive assessment. For example, if the equal values of two parameters have been observed, then the index with the higher entropy but less information will have less effect on the assessment.

The Shannon entropy applied in soil heavy metal pollution assessment is as follows:

$$
\begin{gathered}
H(X)=H\left(p_{1}, p_{2}, \ldots, p_{n}\right)=-k_{1} \sum_{i=1}^{n} p_{i} \ln p_{i} \\
k_{1}=-\ln \left(\frac{1}{n}\right)=\ln (n)
\end{gathered}
$$


$X$ will be uncertain as the function is with $n$ possible pollution results. In the first formula, $\mathrm{K}(k \geq 0)$ is a constant and $p_{\mathrm{i}}$ is observed after $i$ times standardization. $p_{\mathrm{i}}$ can represent the $i^{\text {th }}$ microscopic state of heavy metal pollution in farmland soil. According to rules, if $p_{\mathrm{i}}=0$ exists, then $0 \ln 0=0$ can be achieved. $k_{1}$ plays the role of standardization coefficient, which is calculated as the second formula. $H$ is called the Shannon entropy of the pollution and the Shannon entropy weights are calculated according to the third formula as follows [16]:

$$
\omega_{i}=\frac{1-H_{i}}{m-\sum_{i=1}^{m} H_{i}}
$$

...where $H_{\mathrm{i}}$ is the Shannon entropy of the $i^{\text {th }}$ assessment index while $m$ represents the number of the indexes.

Fuzzy sets theory put forward by Zadeh in 1965 were then used by De Luca and Trimini to make a definition of fuzzy entropy that meets the four important axioms of fuzzy entropy and realize the global measure even when the state is uncertain [17]. In the study, fuzzy entropy is used to measure the fuzzy of the cloud model assessment.

$$
\begin{gathered}
E=-k_{2} \sum_{j=1}^{n}\left[C e_{i} \ln C e_{i}+\left(1-C e_{i}\right) \ln \left(1-C e_{i}\right)\right] \\
k_{2}=-\ln \left(\frac{1}{n}\right)-(n-1) \ln \frac{n-1}{n}
\end{gathered}
$$

...where $C e_{i}$ is the $i^{\text {th }}$ element belonging to $C e$, which is the certainty vector of the cloud model, $\ln 0=0$ exists as regulated, $k_{2}$ plays the role of standardization coefficient (which is calculated as the fifth formula), and $E$ is the fuzzy entropy of $\mathrm{Ce}$ to reveal the fuzzy level.

The cloud model parameter $\left(E_{x}, E_{n}, H_{e}\right)$ is selected in the following formulas double limited in the range of $\left[B_{\min }, B_{\max }\right][18]$.

$$
\left\{\begin{array}{l}
E x=\left(B_{\min }+B_{\text {max }}\right) / 2 \\
E n=\left(B_{\max }-B_{\text {min }}\right) / 6 \\
H e=k
\end{array}\right.
$$

...where $B_{\min }$ and $B_{\max }$ is, respectively, the upper and lower bounds of a quantitative range for a certain qualitative concept, $k$ is a constant that can be adjusted by the threshold of different variables. Let $H_{\mathrm{e}}$ have a liner relationship with $E_{\mathrm{n}}$ as the formula. $H e=k \cdot{ }_{\mathrm{e}} n . k$ controls the atomization degree. When $k=0$ happens, the model will be changed into a membership function. The solution to it is temporarily letting $k=0.1$. The parameters can be calculated in reference to Table 1 , in which $S_{i \text { min }}$ expresses the lower limit of level $i$ while $S_{i \max }$ expresses the upper limit of the level.

The cloud model parameters of different levels are achieved from the corresponding index limits. The cloud
Table 1. Calculation criterion of cloud model parameter $\left(E_{x}, E_{n}\right.$, $\left.H_{e}\right)$.

\begin{tabular}{|c|c|c|c|}
\hline \multirow{2}{*}{ Lever } & \multicolumn{3}{|c|}{$\mathrm{Cd}, \mathrm{Cr}, \mathrm{Pb}, \mathrm{As}, \mathrm{Hg}$} \\
\cline { 2 - 4 } & $E_{x}$ & $E_{n}$ & $H_{e}$ \\
\hline I & $\left(S_{1 \min }+S_{1 \max }\right) / 2$ & $\left(S_{1 \min }+S_{1 \max }\right) / 3$ & $E n / 10$ \\
\hline II & $\left(S_{2 \min }+S_{2 \max }\right) / 2$ & $\left(S_{2 \min }+S_{2 \max }\right) / 3$ & $E n / 10$ \\
\hline III & $\left(S_{3 \min }+S_{3 \max }\right) / 2$ & $\left(S_{3 \min }+S_{3 \max }\right) / 3$ & $E n / 10$ \\
\hline IV & $\left(S_{4 \min }+S_{4 \max }\right) / 2$ & $\left(2 S_{4 \min }+S_{4 \max }\right) / 3$ & $E n / 10$ \\
\hline
\end{tabular}

model is formed with indexes by a cloud generator as shown in Fig. 1.

\section{Evaluation Process}

Evaluating the process of the entropy-cloud model can be described as follows. First, the indexes must be chosen practically and respectively corresponding to a certain level for each one. Second, the cloud model parameter of different levels is achieved from the corresponding index limits. The cloud model is formed with indexes by a cloud generator. Hybrid entropy weights were determined based on Shannon entropy and AHP to generate an entropycloud model of all indicators. Finally, the certainty vector will be calculated to identify pollution level $L$ and fuzzy entropy $E$ of $C e$, which are applied to get two-dimensional $(L, E)$ evaluation results (Fig. 2).

Detailed processing of the entropy-cloud model evaluation is shown as follows.

Firstly, the indexes for soil heavy metal evaluation are chosen according to the China soil environmetal quality standard (GB 15618-1995), which provides the pollution elements and describes how the data are to be comparatively studied. $\mathrm{Cr}, \mathrm{Cd}, \mathrm{Hg}$, and $\mathrm{Pb}$ are the chosen indexes which can be assessed as no pollution, slight pollution, and heavy pollution according to their contents.

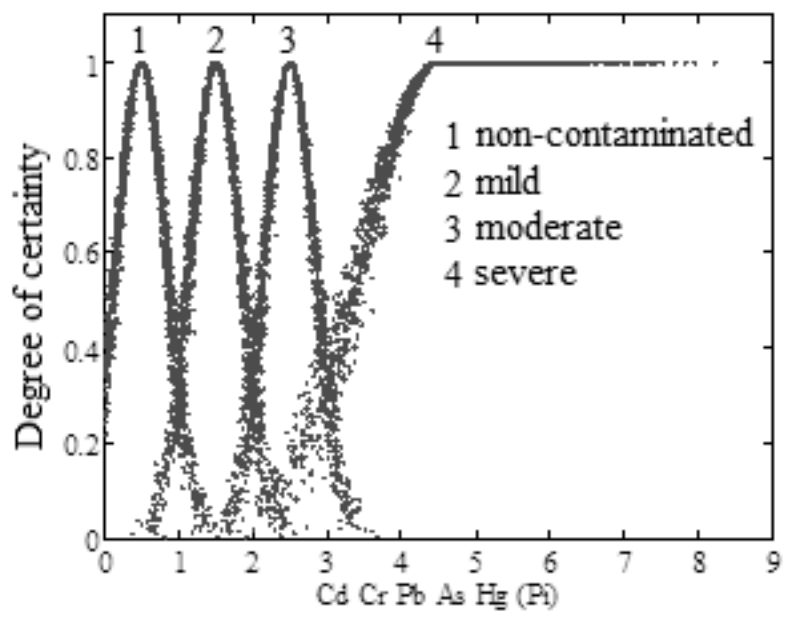

Fig. 1. The cloud model of pollution level formed by assessment indexes. 


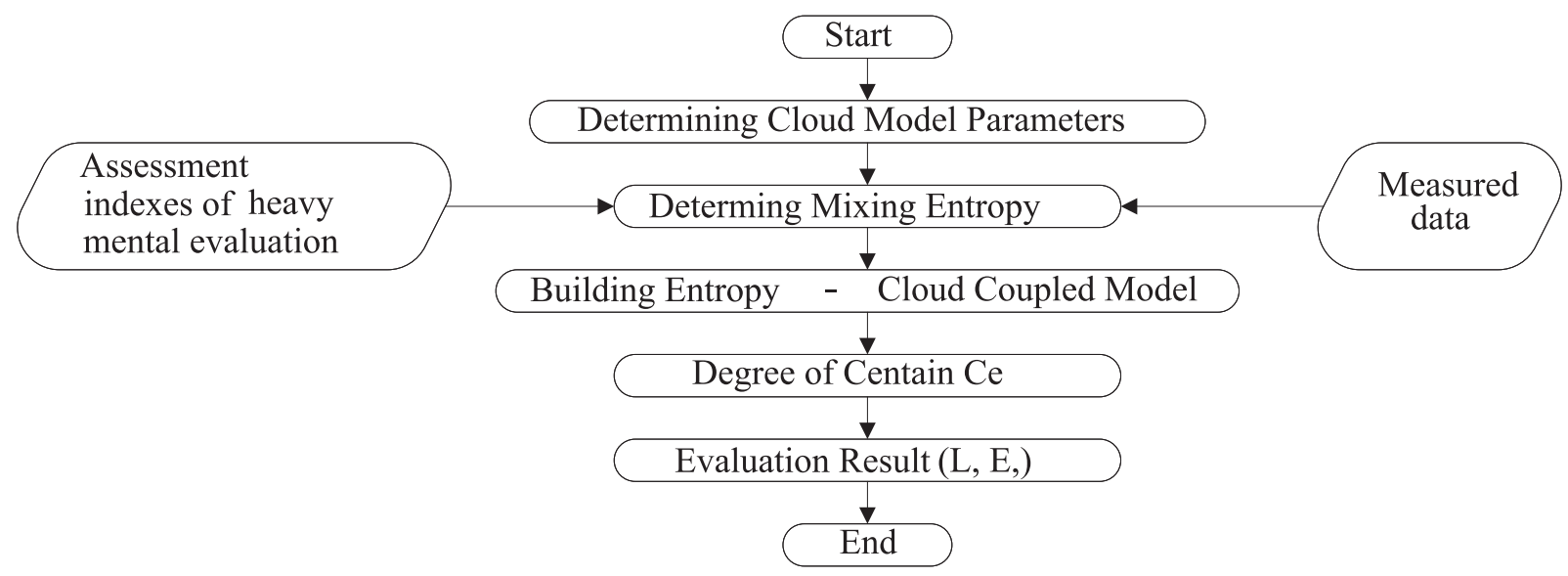

Fig. 2. Evaluation process of the entropy-cloud model.

Secondly, identify the cloud model parameter whose calculation criterion are shown in Table 1. The cloud model parameter of different levels is achieved from the corresponding index limits.

Thirdly, hybrid entropy weights are calculated with the first, second, and third formulas. Entropy weights can vary with different evaluation objects, so the comparison among all the parameters on the influence to the comprehensive assessment should also be taken into consideration. That is also the reason why the Shannon entropy and AHP have been created to calculate the weights.

Significance weight $r_{i}$ is calculated by AHP. The detailed steps are as follows. The sequence of seven soil heavy metal elements should be known for their harm to human health: $\mathrm{Hg}>\mathrm{As}>\mathrm{Cd}>\mathrm{Pb}>\mathrm{Cr}>\mathrm{Cu}>\mathrm{Zn}$. Then, the weight vector $r^{\prime}=(0.4378,0.2608,0.1086,0.1086,0.0442$, $0.0251,0.0149)$ can be acquired through a judgment matrix and consistency check [19]. When $\mathrm{Cu}$ and $\mathrm{Zn}$ are excluded, then the residual elements weights can be normalized to obtain weight vector $r=(0.4692,0.2795$, $0.1164,0.1164,0.04744)$.

According to the first, second, and third functions, Shannon entropy weights of every index $\left(\omega_{i}\right)$ are calculated and Shannon entropy-AHP weight is identified by the seventh formula.

$$
W_{i}=\frac{r_{i} \omega_{i}}{\sum_{i=1}^{m} r_{i} \omega_{i}}
$$

Hybrid entropy weights are proposed aiming at the weights of all indicators to prevent the situation of not combing objective weight with subjective weight in the assessment. Then the entropy-cloud model is established after the identification of hybrid entropy weights.

Fourthly, the certainty of $\mathrm{Ce}_{i}^{\prime}$ is identified by the cloud model with the substitution of the actual measured value $x$ in it. $C e_{i}$ is the $i^{\text {th }}$ element belonging to $C e$, which is the certainty vector of the cloud model. Because of hyper entropy $\mathrm{He}$, the randomness of cloud droplets in a certain range can be described as $\left(x, C e_{i}^{\prime}\right)$ in Figure 1. In this case, hyper entropy can be used to show the uncertainty of different opinions of experts about $x$ belonging to a certain heavy metal pollution concept. $\mathrm{Ce}_{i}^{\prime}$ is the mean of some cloud droplets.

The certainty vector $C e$ is identified by hybrid entropy weights of $C e_{i}$ about all indexes to take the max $(L)$ of $C e$ as the level of evaluation model. $C e_{i}$ is the $i^{\text {th }}$ element belonging to $C e$, which is the certainty vector of the cloud model.

Fifthly, in result assessment, grade evaluation cannot reflect detailed conditions about pollution levels because of the different certainty distributions in different indexes. So fuzzy entropy is taken to provide a new solution. The fuzzy entropy $E$ of $C e$ is calculated in the fourth and fifth functions, which can be applied to get two-dimensional $(L, E)$ evaluation results.

Table 2. Selected pollution parameters under each single factor of soils.

\begin{tabular}{|c|c|c|c|}
\hline \multirow{2}{*}{ Level } & \multicolumn{3}{|c|}{$\mathrm{Cd}, \mathrm{Cr}, \mathrm{Pb}, \mathrm{As}, \mathrm{Hg}$} \\
\cline { 2 - 4 } & $E_{x}$ & $E_{n}$ & $H_{e}$ \\
\hline I & 0.50 & 0.33 & 0.033 \\
\hline II & 1.50 & 0.33 & 0.033 \\
\hline III & 2.50 & 0.33 & 0.033 \\
\hline IV & 4.50 & 1.00 & 0.10 \\
\hline
\end{tabular}

Table 3. Heavy metal pollution index weights.

\begin{tabular}{|c|c|c|c|}
\hline Indexes & $\begin{array}{c}\text { Entropy } \\
\text { Weight } \omega\end{array}$ & $\begin{array}{c}\text { AHP } \\
\text { Weight } r\end{array}$ & $\begin{array}{c}\text { Mixed Entropy } \\
\text { Weight } W\end{array}$ \\
\hline $\mathrm{Cd}$ & 0.224 & 0.1164 & 0.1168 \\
\hline $\mathrm{Hg}$ & 0.278 & 0.4692 & 0.5845 \\
\hline $\mathrm{Pb}$ & 0.109 & 0.1164 & 0.0569 \\
\hline $\mathrm{Cr}$ & 0.236 & 0.0474 & 0.0501 \\
\hline $\mathrm{As}$ & 0.153 & 0.2795 & 0.1916 \\
\hline
\end{tabular}



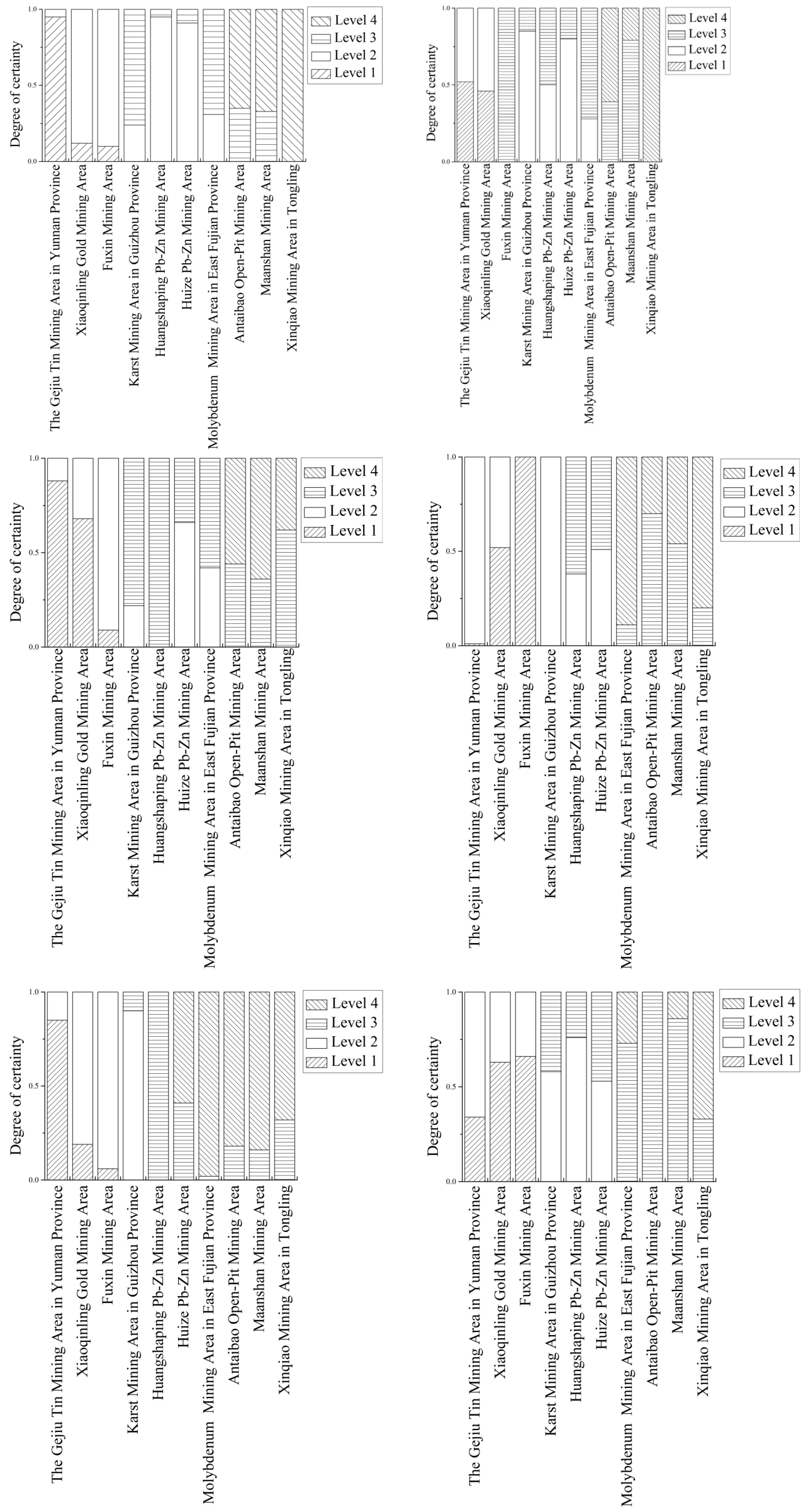

Fig. 3. Stack figure of certainty under different degrees. 
Table 4. Comparison among evaluation results of soil heavy metal pollution.

\begin{tabular}{|c|c|c|c|c|c|}
\hline Mining area & Literature & $\begin{array}{l}\text { BP Neural } \\
\text { Network }\end{array}$ & $\begin{array}{l}\text { Variable fuzzy } \\
\text { sets }\end{array}$ & Cloud model & Entropy-cloud model \\
\hline Gejiu Tin Deposit mining area & III & III & IV & III & (I, fuzzy) \\
\hline Antaibao Open-cast Area & I & II & I & I & (I, less fuzzy) \\
\hline $\begin{array}{c}\text { East Fujian molybdenum mining } \\
\text { area }\end{array}$ & II & III & II & II & (II, less fuzzy) \\
\hline Xinqiao mining area in Tong ling & IV & III & III & IV & (III, less fuzzy) \\
\hline Fuxin mining area & II & III & III & III & (III, less fuzzy) \\
\hline Karst mining area & III & III & IV & III & (IV, less significant) \\
\hline Huang shaping lead mining area & IV & IV & IV & IV & (IV, less significant) \\
\hline Huize $\mathrm{Pb}-\mathrm{Zn}$ Mining Area & IV & IV & IV & IV & (IV, significant) \\
\hline Xiaoqinling gold mining area & IV & IV & IV & IV & (IV, significant) \\
\hline Maanshan mining area & IV & IV & IV & IV & (IV, significant) \\
\hline
\end{tabular}

The evaluation results' belonging to different fuzzy levels of each grade are expressed by $E$, which further reveals the complexity of the pollution. $E$ is regulated to keep the corresponding relationship with the fuzzy degree belonging to each level as follows: $(0,0.25),(0.25$, $0.50),(0.50,0.75)$, and $(0.75,1)$ represent, respectively, correlated, positively correlated, positively fuzzy, and fuzzy. The soil tested to be correlated and positively correlated is known to be less complex for its relative uniformity in grade of indexes while another shows the opposite phenomenon identified to be positively fuzzy and fuzzy. The soil with high complexity can be tested in different assessment methods but gain contradictory results.

The fuzzy entropy $E$ can assess the soil heavy metal pollution from two aspects of level and complexity to comprehensively solve the inconsistency of degree belonging among different indexes.

\section{Results}

\section{Data Analysis Results}

To verify the feasibility and validity of the entropycloud model in the evaluation, farmland soils from 10 mining areas have been studied for pollution [20-29]. The cloud model parameter is calculated as Table 1 , and the results are shown in Table 2. Index weights of heavy metal pollution is identified by the first, second, third and the seventh formulas and is as shown in Table 3. Stack diagram can be seen in Fig. 3 to reveal the certainty of each index in which level $i(\mathrm{i}=\mathrm{I}$, II, III, IV) represents the four levels. The fuzzy entropy $E$ of $C e$ is calculated. The extreme value of each level has been taken as the gas bubble point to generate the final results as shown in Fig. 4.

\section{Comparison of Reference Method Results}

To verify the reliability of the entropy-cloud model in the evaluation, a comparative study has been researched with the methods of variable fuzzy sets, BP neural network, and cloud model whose analysis results are listed in Table 4 [30].

\section{Discussion of Results}

The degree can be identified differently when a different method is used even for the same index. In this case, only three of the 10 mining area farmland soils were identified at the same level when researched in different methods. The Gejiu tin deposit mining area is the one that shows great inconsistency under a different method. The Gejiu area is degreed as level I. It has been analyzed that the certainty degree of level I is greatest (Fig. 3) when $\mathrm{Hg}$ is taken as the research index. $\mathrm{Hg}$ has the hybrid entropy of 0.541 , which is quite different from the other weights that lead to a different final result. The above problem caused by different methods has never been explained in detail before. Through the above analysis the problem is that the farmland soil with higher complexity usually has a different result according to different methods that can result from inconsistency of degree belonging to the index. In this case, the farmland soil of the Gejiu tin deposit mining area is with high complexity and fuzzy degree belonging, so the inconsistency of the results turns out to be more obvious.

As shown in Fig. 4, the studied mining area can be divided into four categories according to their pollution extent. From high to low, they are in the sequence of the Antaibao open-cast area, the Gejiu tin deposit mining area, the East Fujian molybdenum mining area, the Xinqiao mining area in Tongling, Xiaoqinling gold mining area, Custer antimony mining area, Huang shaping lead mining 


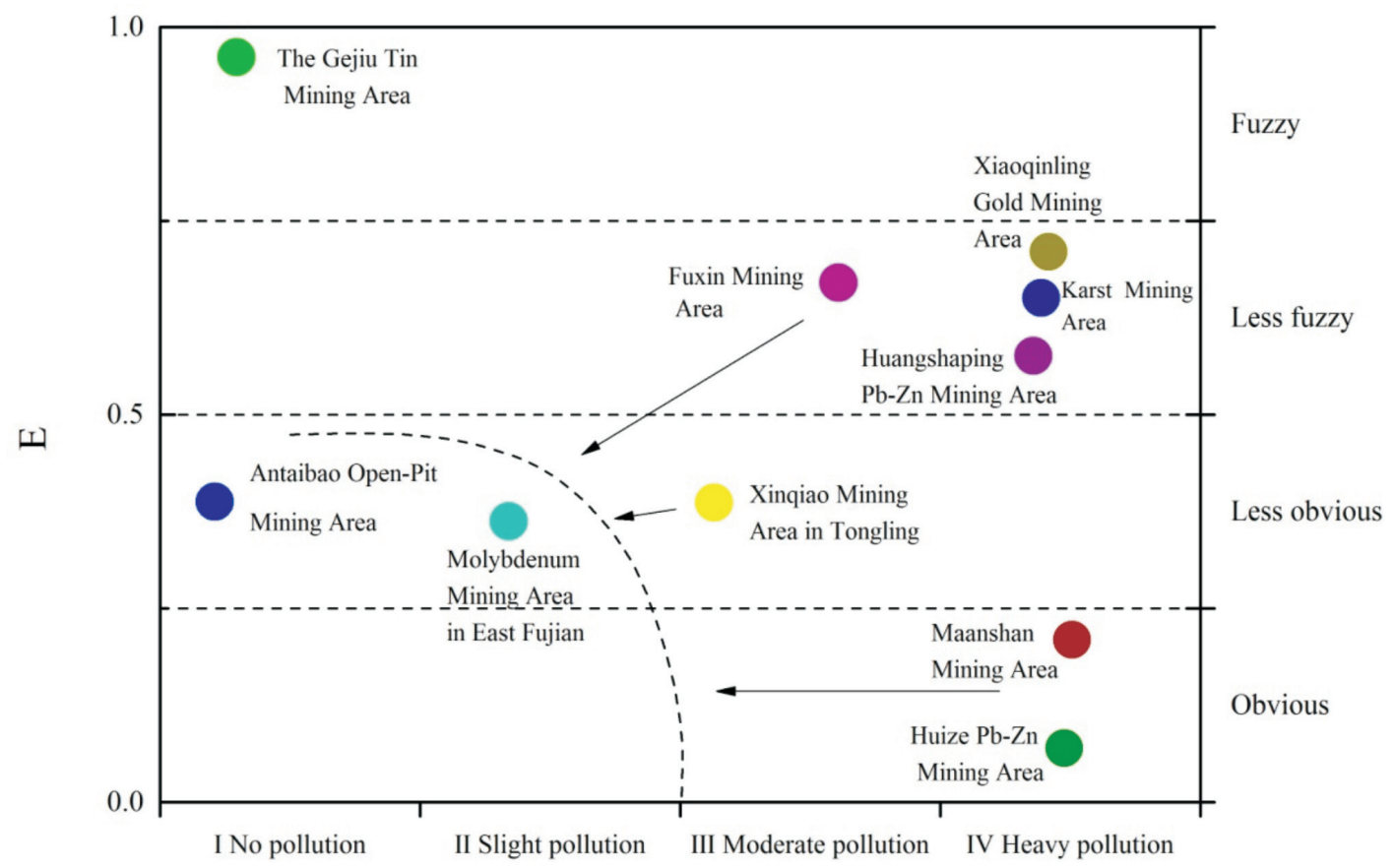

Fig. 4. Bubble chart of soil heavy metal pollution assessment.

area, Maanshan iron mine, and Huize $\mathrm{Pb}-\mathrm{Zn}$ mining area. The actual utilization should be taken into consideration as the pollution level is consistent with the farmland soil obstacle.

Fig. 4 points out the pollution control strategy indicated by arrows that stretch from high degree and complexity to low degree and complexity until reaching the final region $\mathrm{G}$, whose space size depends on a practical goal.

The biggest certainty is bubble size. It can be seen from the diagram that bubble area increases as the degree becomes more obvious, indicating that the maximum and minimum of a certainty are in the positive correlation with the obvious level of degree belonging.

\section{Conclusions}

As three problems exist in the evaluation of soil heavy metal pollution, the information entropy and cloud model is applied to propose the entropy-cloud model because soil heavy metal pollution cannot be assessed accurately using only one method for analysis, especially when the degree belonging to the index is inconsistent. Firstly, the fuzziness and randomness of the assessment is expressed effectively by the cloud model. Secondly, subjective and objective factors have been taken into comprehensive consideration by hybrid entropy. Finally, the second dimensional parameter $E$ is applied to assess the soil heavy metal pollution from two aspects of level and complexity. The two-dimensional model takes both levels from the macro aspect and complexity from the micro aspect into consideration. The entropy-cloud model is proved to be effective and intuitive, providing a new solution for soil heavy metal pollution assessment. The entropy-cloud model can also be applied into discussions on zoning of soil environmetal risk control and remediation contaminated by heavy metals on regional scale, and the evaluation of other relevant heavy metals contamination fields.

\section{Acknowledgements}

This research is supported by the Basic Research Program of Dezhou University (Grant No. 2015skrc03); Shandong Province Crucial R\&D Plan Project (2015GGX105008); Shandong Province Natural Science Fund (ZR2013GL001); the Ministry of Education, Humanities and Social Sciences Youth Fund (11YJCZH119); and the Food Economics and Management Research Base, which is a College of Humanities and Social Science research base in Shandong Province. The authors are thankful to the editors and anonymous reviewers for their careful reading, constructive comments, and fruitful suggestions to improve this manuscript.

\section{Author Contributions}

All authors contributed to the theory and analysis developed in the manuscript and in finalizing the manuscript. All authors have read and approved the final manuscript.

\section{Conflicts of Interest}

The authors declare no conflict of interest. 


\section{References}

1. JIANG Y., HU X.F., SHU Y., LUO F. Effects of mining activities on heavy metal pollution and soil enzyme activities of paddy fields. Chinese Journal of Soil Science. 46 (2), 494, 2015.

2. ZENG X.B., XU J.M., HUANG Q.Y. Some deliberations on the issues of heavy metals in farmlands of China. Acta pedological sinica. 50 (1), 186, 2013.

3. CHEN T.B., LI M., YANG J., ZHOU X.Y. Discussion on zoning of soil environmetal risk control and remediation contaminated by heavy metals on regional scale. Bulletin of Chinese Academy of Sciences. 29 (3), 321, 2014.

4. LU S.J., WANG Y.Y., HE L.H. Ecological risk of heavy metals in agricultural soils assessed by risk assessment code. Environmetal chemistry. 33 (11), 1857, 2014.

5. LIU J., TENG Y.G., CUI Y.F., WANG J.S. Review in ecological risk assessment methods for heavy metal polluted soils. The Administration and Technique of Environmetal Monitoring. 19 (3), 6, 2007.

6. JI Y., FENG Y., WU J. Using geo accumulation index to study source profiles of soil dust in China. Journal of Environmetal Sciences. 20 (5), 571, 2008.

7. LI D., CHENG D., SHI X. Uncertainty reasoning based on cloud models in controllers. Computers \& Mathematics with Applications. 35 (3), 99, 1998.

8. LI D.Y., LIU C.Y. Study on the universality of the normal cloud model. Engineering Science. 6 (8), 28, 2004.

9. WANG S., LI D., SHI W. Cloud model-based spatial data mining. Geographic Information Sciences. 9 (1), 60, 2003.

10. LIU Y.C., MA Y.T., ZHANG H.S. A method for trust management in cloud computing: Data coloring by cloud watermarking. International Journal of Automation and Computing. 8 (3), 280, 2011.

11. LIU D.F., WANG D., DING H. A risk assessment method based on RBF artificial neural network-cloud model for urban water disaster. Yellow River. 1 (1), 8, 2014.

12. LIU C.Y., LI D.Y., DU Y. Some statistical analysis of the normal cloud model. Information and Control. 34, (2), 236, 2005.

13. ZHANG Z.B., WANG K., PU R.F. Evaluation for the heavy metal pollution in soils of Jin chang City based on double weighing factor s of fuzzy mathematical model. Journal of Northwest Normal University (Natural Science). 45 (2), 89, 2009.

14. LIU D.F., WANG D., DING H. Eutrophication assessment by entropy-cloud model, SHUILI XUEBAO. 45 (10), 1214, 2014.

15. SHANNON C.E. A mathematical theory of communication. ACM SIGMOBILE: Mobile Computing and Communications Review. 5 (1), 53, 2001.

16. ZADEH L.A. Probability measures of fuzzy events. Journal of Mathematical Analysis and Applications. 23 (2), 421, 1968.
17. ZHANG J.G., VIJAY P.S. Information Entropy: Theory and Application. Beijing: China Water Power Press. 45, 2012.

18. DU X.Y., YIN Q.J., HUANG K.D. Transformation between qualitative variables and quantity based on cloud models and its application. Systems Engineering and Electronics. 30 (4), 772, 2008

19. LI X.M., WANG Z.W., TANG X.Q. Determining weights of heavy metal contaminations and its application to soil environmetal quality assessment. Journal of AgroEnvironment Science. 26 (6), 2281, 2007.

20. QIAO P.W., ZHOU X.Y., YANG J., LEI M., CHEN T.B. Heavy metal pollution and ecological risk assessment of Datun basin in the Gejiu tin mining area, Yunnan Province. Geological Bulletin of China. 33 (8), 1253, 2014.

21. XU Y.N., KE H.L., ZHAO A.I. Assessment of heavy metals contamination of farmland soils in some gold mining area of xiao Qinling .Chinese Journal of Soil Science. 38 (4), 732, 2007.

22. LI Y.X., XU L.C., XIONG X. The spatial structure feature of heavy metals in agricultural soil of mining city: A case study of Fuxin, China. Acta Scieniae Circum stantiae. 27 (4), 679, 2007.

23. LU S.J., WANG Y.Y., HE L.H. Heavy metal pollution and ecological risk assessment of the Paddy soils near a $\mathrm{Pb}-\mathrm{Zn}$ mine in Guiyang Country. Hunan Province. Environmetal Chemistry. 34 (3), 591, 2015.

24. LU S.J., WANG Y.Y., HE L. H. Heavy metal pollution and ecological risk assessment of the Paddy Soils around a $\mathrm{Pb}-\mathrm{Zn}$ mine in Huize Country. Ecology and Environmetal Sciences. 23 (11), 1832, 2014.

25. JIA T., JIA Y.Y., YU S.J. Pollution of molybdenum and heavy metals of the soils and rice near a molybdenum mining site in eastern Fujian. Environmetal Monitoring in China. 31 (1), 45, 2015.

26. LIU L.F., LONG J., WAN H.F. Distribution characteristics and risk assessment of heavy metals in agricultural soils in an abandoned antimony smelter in Guizhou Karst areas. Soils. 45 (6), 1036, 2013.

27. LIU H. Research on pollution assessment of Heavy metal to the soil in Maanshan key mining area. Hefei University of Technology. 38, 2012.

28. QIN J.M., BAI Z.K. The content and pollution assessment of heavy metal in reclaimed mediums and plants at Antaibao opencast mine. Journal of Soil and Water Conservation. 27 (1), 176, 2013.

29. WANG Y.Q. Pollution Assessment and Source Apportionment of Heavy Metals in Soils around XinQiao Mining Area in Tongling, Anhui Province. Hefei University of Technology. 52, 2012.

30. YI H.M., ZHOU S.L., WU S.H. An integrated assessment for regional heavy metal contamination in soil based on normal fuzzy number. Acta Scientiae Circumstantiae. 33 (4), 1127, 2013 